\title{
Inflammatory Myofibroblastic Tumor of the Retroperitoneum Including Chronic Granulomatous Inflammation Suggesting Tuberculosis: A Case Report
}

\author{
Younglim Kim ${ }^{1}$, Ji Won Park ${ }^{1}$, Sungwhan Kim, Kil-Yong Lee ${ }^{1}$, Jeongmo Bae², Yoon Kyung Jeon², Ji Min Im², \\ Seung-Bum Ryoo ${ }^{1}$, Seung-Yong Jeong ${ }^{1}$, Kyu Joo Park ${ }^{1}$ \\ Departments of ${ }^{1}$ Surgery and ${ }^{2}$ Pathology, Seoul National University College of Medicine, Seoul, Korea
}

\begin{abstract}
An inflammatory myofibroblastic tumor (IMT) is a solid tumor of unknown etiology frequently affecting children and young adults and commonly affecting the lung or orbital region. We present a case involving a 41-year-old man who had an IMT combined with Mycobacterium tuberculosis infection in the retroperitoneum. He presented with only pain in the right lower abdomen without accompanying symptoms; a retroperitoneal mass was found on computed tomography. The tumor had invaded the end of the ileum and was attached to the omentum, so mass excision could not be performed. The tumor was completely excised surgically and had histological features diagnostic of an IMT. Histologic findings of the omentum were positive for Ziehl-Nielsen staining for acid-fast bacilli and for a positive polymerase chain reaction for $M$. tuberculosis. The patient had no apparent immune disorder. These findings made this case exceptional because IMTs, which are mostly due to atypical mycobacteria, have been found mainly in immunocompromised patients.
\end{abstract}

Keywords: Inflammatory myofibroblastic tumor; Spindle cell proliferation; Mycobacterium tuberculosis

\section{INTRODUCTION}

An inflammatory myofibroblastic tumor (IMT) is an unusual solid tumor that most often affects children and young adults [1]. Whether this type of tumor is benign or malignant is not clear, and its cause is unknown [2]. The lung and the orbit are the most frequent occurrence sites; however, the lesions may originate at any site in the body, including the abdomen [3]. We present a rare and interesting case of an IMT in the retroperitoneum in a 41-year-old man with abdominal pain.

Received: February 20, 2018 - Accepted: May 9, 2018

Correspondence to: Ji Won Park, M.D.

Department of Surgery, Seoul National University College of Medicine, 101 Daehak-ro, Jongno-gu, Seoul 03080, Korea

Tel: +82-2-2072-2325, Fax: +82-2-766-3975

E-mail: sowisdom@gmail.com

ORCID code: https://orcid.org/0000-0003-0046-8175

(C) 2019 The Korean Society of Coloproctology

This is an open-access article distributed under the terms of the Creative Commons Attribution NonCommercial License (http://creativecommons.org/licenses/by-nc/4.0) which permits unrestricted noncommercial use, distribution, and reproduction in any medium, provided the original work is properly cited.

\section{CASE REPORT}

This study is a retrospective review of a case, written consent from the patient was not required. So this case study was exempted from approval and informed consent by the Institutional Review Board of Seoul National University Hospital.

A 41-year-old man presented with right lower quadrant pain. Symptoms had been intermittently present for 2 weeks. He had no history of fever, nausea, or vomiting, and he had no changes in bowel habits or blood in the stool. On physical examination, his abdomen was soft and flat, and evidence of peritoneal irritation was lacking. Routine laboratory test results were within normal limits except for the elevation of C-reactive protein to $13.15 \mathrm{mg} /$ $\mathrm{dL}$ (normal, $0.5-1.0 \mathrm{mg} / \mathrm{dL}$ ). Chest X-ray revealed old tuberculosis sequelae (Fig. 1). An abdominal computed tomography scan revealed neither free gas nor blood in his abdomen. However, a $3.4-\mathrm{cm}$ mass was detected in the right retroperitoneal space. The patient was hospitalized for further evaluation of the retroperitoneal mass. The mass had encroached on the right ureter and encased the mesentery vessels in the ileocolic area (Fig. 2). Carcinoembryonic antigen and carbohydrate antigen 19-9 levels after ad- 


\section{$\begin{aligned} \text { Annals of } & \text { Inflammation Sugges } \\ \text { Coloproctology } & \text { Younglim Kim, et al. }\end{aligned}$}

mission were $0.7 \mathrm{ng} / \mathrm{mL}$ (normal, $0-5 \mathrm{ng} / \mathrm{mL}$ ) and $3.4 \mathrm{U} / \mathrm{mL}$ (normal, 0-37 U/mL), respectively. On day 2 of hospital admission, an ileocecectomy of the mass was performed.

The gross tumor was found to be $5 \mathrm{~cm}$ in maximal diameter and only confined to the subserosal layer of the terminal ileum. Bleed-

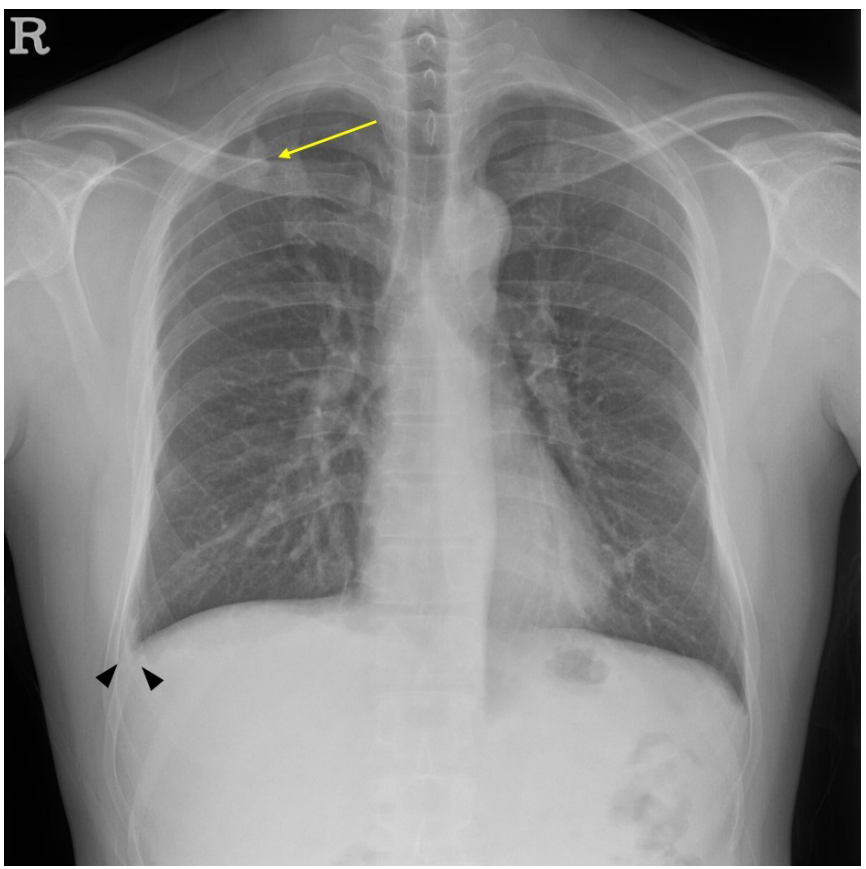

Fig. 1. Nodular opacity in the right upper lung field indicates sequela of tuberculosis (arrow). Right pleural effusion is observed (arrowheads).

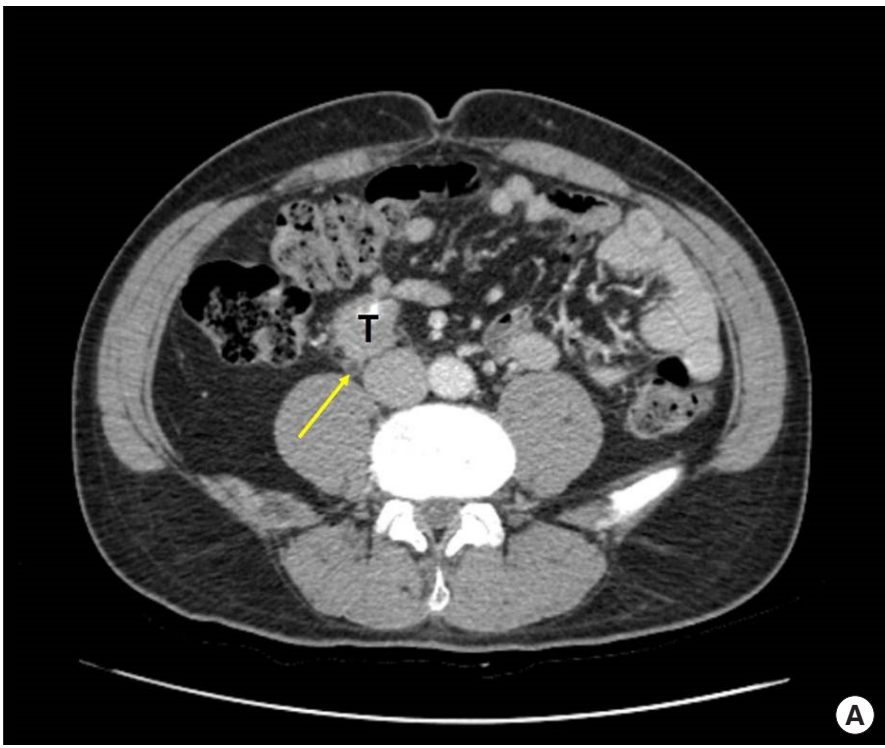

ing and necrosis within the tumor were observed. In addition, no specific findings, such as masses or ulcers, were observed on the mucosa and the serosa layer (Fig. 3). Pathological examination confirmed the diagnosis of an IMT by demonstrating a spindlecell proliferative lesion (Fig. 4). The omentum attached to the ileocolic area was resected. The lesion contained chronic granulomatous inflammation consistent with tuberculosis and was not separate from the IMT (Fig. 5). The postoperative course was uneventful, and the patient was discharged 7 days after surgery. At 4 months postoperatively, the patient was well, without radiological evidences of disease recurrence. He also began treatment for tuberculosis in histologic examination.

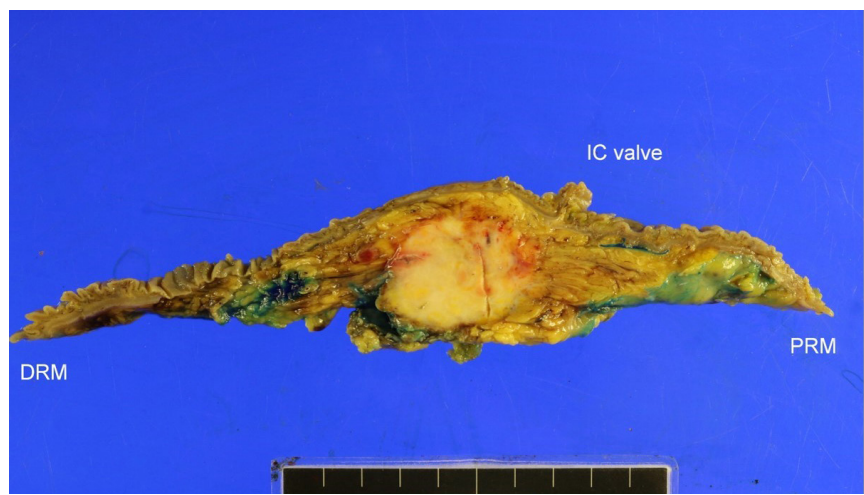

Fig. 3. Gross appearance of a tumor mass with a cut surface showing a relatively circumscribed, solid, white, firm, well-demarcated tumor. IC, ileocecal; PRM, proximal resection margin; DRM, distal resection margin.

Fig. 2. The tumor (T) (A) is compressing the right ureter (yellow arrow), resulting in hydronephrosis and (B) has invaded the terminal ileum

(white arrow) surrounding mesentery vessels.

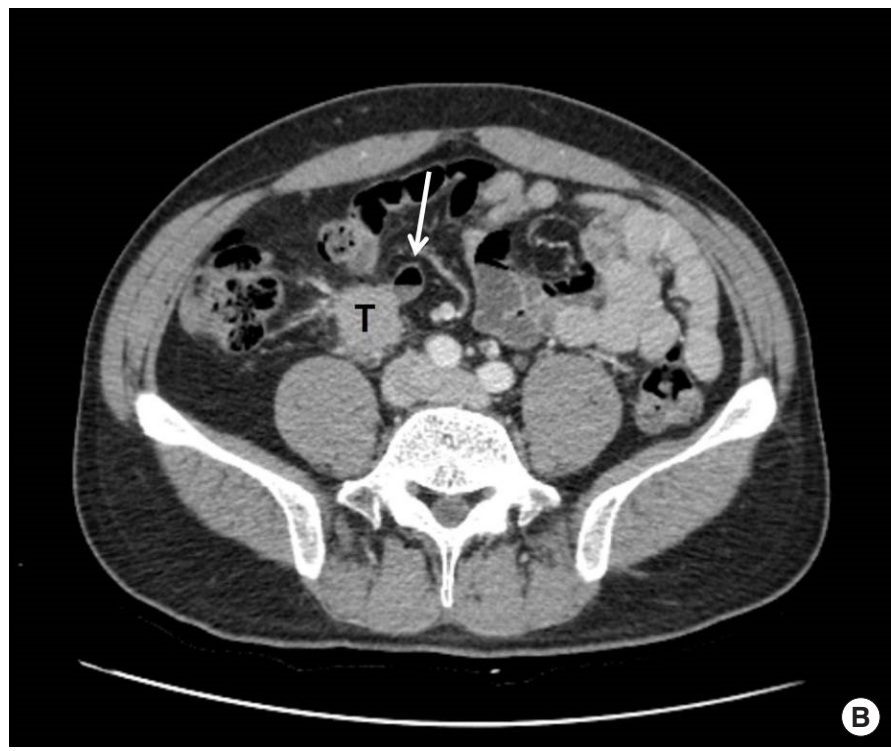




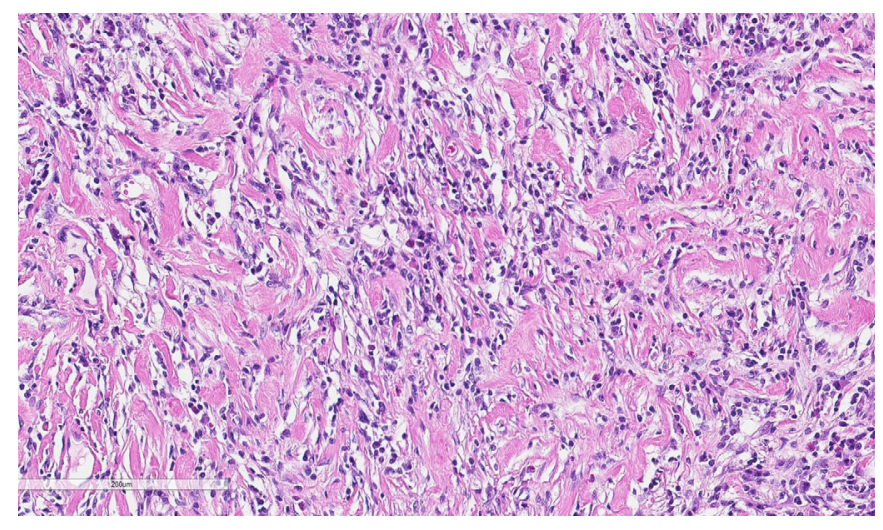

Fig. 4. Section showing a tumor composed of spindle-shaped fibroblastic cells with moderately pleomorphic hyperchromatic nuclei and prominent nucleoli $(\mathrm{H} \& \mathrm{E}, \times 200)$.

\section{DISCUSSION}

IMTs occur more frequently during childhood, and their most common site is the lungs. The term IMT, which was commonly referred to as an inflammatory pseudotumor in previous literature, was initially proposed in 1990 during a study of inflammatory lesions of the pulmonary system [3]. Although its histopathologic nature is benign, it may not be differentiated from a malignant tumor because of its local invasiveness and tendency to recur [4]. Furthermore, it may present as a complicated mass, resulting in a diagnostic dilemma. That the cause remains unknown is another issue. Several associations have been reported between IMTs and infections; however, in some cases, an IMT is thought to result from inflammation following minor trauma or surgery or to be associated with another malignancy $[1,5]$. Only 30 cases of mycobacterial IMTs have been reported in the English literature. Most were found in immunocompromised patients. Rarely, did patients with an IMT have immune competence. Only one case was reported to be due to Mycobacterium tuberculosis infection [5-7]. Although seven cases of IMTs affecting the small intestine have previously been reported in the English literature, only our case presented a tumor of the small intestine that was caused by $M$. tuberculosis. However, limited supporting information is available, and the mechanism behind the development of IMTs is still unclear.

The clinical presentation, radiological appearance and macroscopic pattern of mycobacterial IMTs make them extremely indistinguishable from malignant tumors. Neither fine needle aspiration nor frozen section examination can be used to confirm the presence of an IMT, so most cases are diagnosed based on a definitive pathologic report after surgical resection [8]. Therefore, surgical resection may be an appropriate treatment when symptoms are due to the mass effect and when differentiation from cancer is difficult, as in this case [9-11]. However, the treatment strategy may vary depending on the cause of the disease.
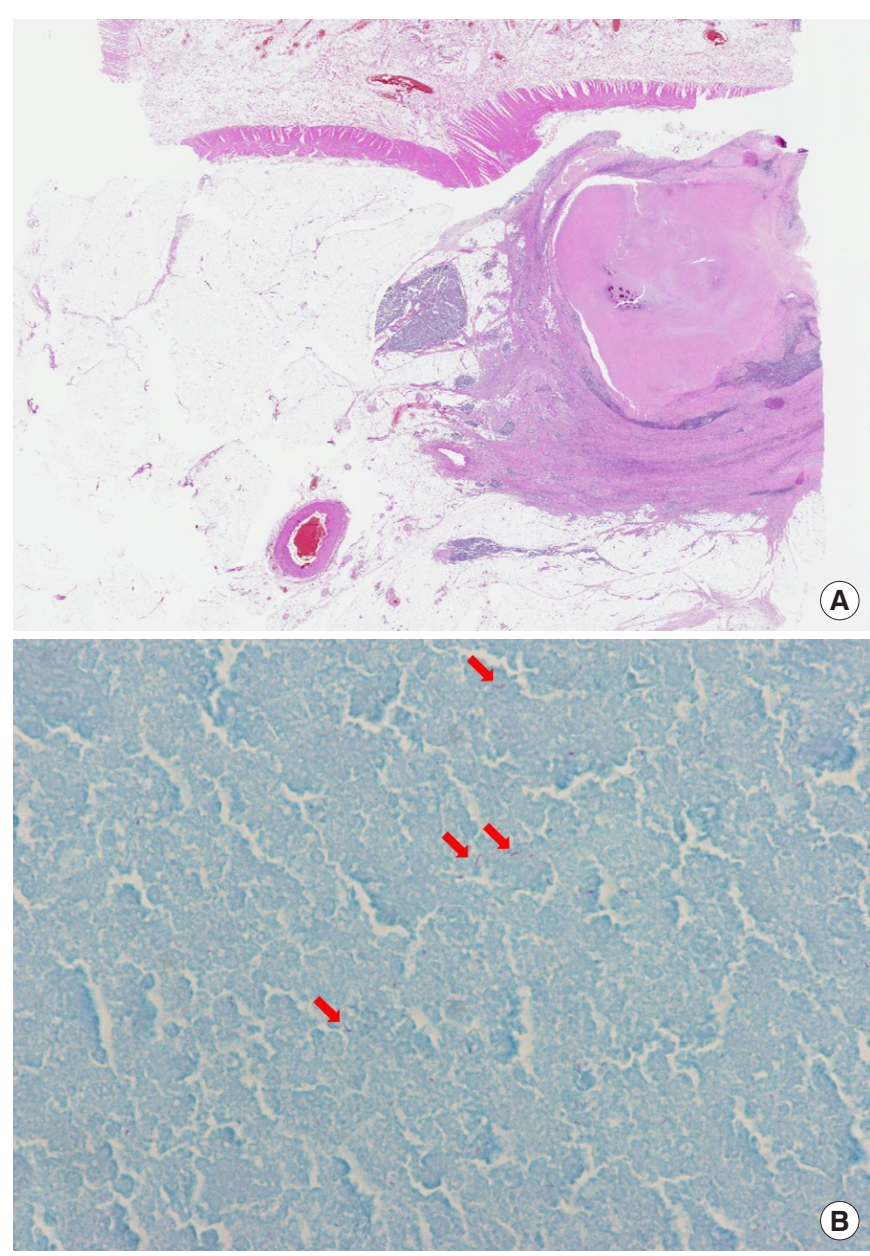

Fig. 5. (A) The tumor contains numerous granulomas characterized by central caseous necrosis. (B) Several bacilli (arrows) are seen in the Ziehl-Nielsen stain (acid-fast bacilli, $\times 600$ ).

Although complete surgical resection is the primary treatment modality for IMTs and radiation therapy and steroid therapy may be considered, the effectiveness of such treatments is limited. The incidence of recurrence has been reported to be $2 \%$ to $25 \%$, depending on the location of the tumor, but recurrence has been reported to be very rare after complete resection of a single tumor in the abdomen [1, 12-14].

In conclusion, the relationship between an IMT and tuberculosis could not be accurately demonstrated in this case, but it was of value as evidence. Also, the primary therapeutic approach was complete resection of the tumor to confirm the histological diagnosis, to allow differentiation from other small intestine tumors, and to result in a favorable outcome.

\section{CONFLICT OF INTEREST}

No potential conflict of interest relevant to this article was reported. 


\section{REFERENCES}

1. Gleason BC, Hornick JL. Inflammatory myofibroblastic tumours: where are we now? J Clin Pathol 2008;61:428-37.

2. Choi AH, Bohn OL, Beddow TD, McHenry CR. Inflammatory myofibroblastic tumor of the small bowel mesentery: an unusual cause of abdominal pain and uveitis. J Gastrointest Surg 2011;15: 584-8.

3. Zuo T, Fu J, Ni Z, Chen B. Pulmonary inflammatory Myofibroblastic tumor indistinguishable from tuberculosis: a case report in a five-year-old child with hemoptysis. J Cardiothorac Surg 2017; 12:112.

4. Karnak I, Senocak ME, Ciftci AO, Cağlar M, Bingöl-Koloğlu M, Tanyel FC, et al. Inflammatory myofibroblastic tumor in children: diagnosis and treatment. J Pediatr Surg 2001;36:908-12.

5. Coffin CM, Dehner LP, Meis-Kindblom JM. Inflammatory myofibroblastic tumor, inflammatory fibrosarcoma, and related lesions: an historical review with differential diagnostic considerations. Semin Diagn Pathol 1998;15:102-10.

6. Yin HL, Zhou XJ, Wu JP, Meng K, Sun YM. Mycobacterial spindle cell pseudotumor of lymph nodes after receiving Bacille CalmetteGuerin (BCG) vaccination. Chin Med J (Engl) 2004;117:308-10.

7. Manolaki N, Vaos G, Zavras N, Sbokou D, Michael C, Syriopoulou V. Inflammatory myofibroblastic tumor of the liver due to
Mycobacterium tuberculosis in an immunocompetent girl. Pediatr Surg Int 2009;25:451-4.

8. Cross DL, Switter DJ. Fibroinflammatory pseudotumor of the submandibular gland. Head Neck 1996;18:465-8.

9. Koyuncuer A. Inflammatory myofibroblastic tumor of the smallbowel mesentery: a case report of nonspecific clinical presentation and a review of the literature. Int J Surg Case Rep 2014;5:1214-7.

10. Rezaii Salim M, Vahedi H, Salimi Z, Froutan H, Sotoudeh M. Inflammatory myofibroblastic tumor of the small bowel: a case report. Middle East J Dig Dis 2011;3:134-7.

11. Goldblum JR, Folpe AL, Weiss SW. Borderline and malignant fibroblastic/myofibroblastic tumours. In: Enzinger \& Weiss's Soft Tissue Tumors. 6th ed. Philadelphia: W.B. Saunders; 2013. p. 304-7.

12. Ong HS, Ji T, Zhang CP, Li J, Wang LZ, Li RR, et al. Head and neck inflammatory myofibroblastic tumor (IMT): evaluation of clinicopathologic and prognostic features. Oral Oncol 2012;48: 141-8.

13. Chen YF, Zhang WD, Wu MW, Ou-Yang D, Zhang Q. Inflammatory myofibroblastic tumor of the head and neck. Med Oncol 2011; 28 Suppl 1:S349-53.

14. Van Weert S, Manni JJ, Driessen A. Inflammatory myofibroblastic tumor of the parotid gland: case report and review of the literature. Acta Otolaryngol 2005;125:433-7. 